\title{
Corpos diaspóricos e masculinidades negras: Uma leitura de Todo mundo odeia o Chris a partir da
}

\author{
decolonialidade
}

\author{
Cuerpos diapóricos y masculinidades negras: \\ Una lectura de todo el mundo odia a Chris a partir de la decolonialidad
}

\author{
Diasporic bodies and black masculinities: \\ A reading from Everyone hates Chris from decoloniality
}

Ludmila Pereira de almeida ${ }^{1}$

\begin{abstract}
Resumo
Nosso principal objetivo é discutir como os efeitos de língua/linguagem dizem/fazem(AUSTIN, 1998) corpos subalternizados e de como isso pode nos fornecer traços para uma leitura crítica que vise o pensamento decolonial(WALSH, 2009) e o não extermínio, físico e simbólico, de vidas e outras masculinidades. Para fins de problematizar, especialmente, a visibilidade/invisibilidade dos corpos negros e a construção de prefigurações sobre tal corpo denominado de masculino, trazemos o seriado sitcom Todo mundo odeia o Chris(2005) traduzido-dublado como índice de como as narrativas midiáticas reiteram as experiências sociais e performam atos de linguagem constituindo espaços e formas de opressão. Isso tendo como perspectiva a crítica à trajetória histórica imperial nas américas que se funda a partir da colonialidade do poder e do saber, juntamente com a ideia de hierarquização de raça(QUIJANO, 2005). Nossa discussão se pauta na construção das masculinidades negra e dos atos metapragmáticos evocados, o situando dentro de um duplo narcisismo(FANON, 2008), de um corpo desejado, viril, exótico ao mesmo tempo que é visto como ameaça, concorrência que precisa ser controlado. O seriado norte-americano ao ser dublado é reentextualizando ao contexto local brasileiro e se insere em diálogo dentro do percurso da diáspora dos corpos negros e da luta transacional antirracista e de re-existência desses corpos. Performando e retomando atos de fala que exercem ações reais sobre os sujeitos negros em contexto opressor, ditando vidas que importam ao configurar, como uma das consequências, a neurose racial brasileira(GONZALEZ, 1984) que apenas lê T.M.O.C como um entretenimento sendo que a todo instante ele traz a denúncia da violência racial.
\end{abstract}

Palavras-Chave: Corpos negros, masculinidades negras, Todo mundo odeia o Chris, mídia, colonialidade/decolonialidade.

\section{Resumen}

El objetivo es entonces discutir cómo dicen que los efectos del lenguaje dicen/hacen (AUSTIN, 1998) cuerpos subordinados y cómo puede proporcionar los rasgos de una lectura crítica para el pensamiento descolonial (WALSH, 2009) y no la muerte, física y simbólica de vidas y otras masculinidades. A los efectos de cuestionamiento, sobre todo, la visibilidad / invisibilidad de los cuerpos negros y prefiguraciones de construcción en un cuerpo masculino llamado así, llevar la comedia Todo el mundo odia a Chris (2005), traducido como un índice de cómo las narrativas de los medios reiteran la experiencias sociales y actos de lenguaje performam que constituyen espacios y las formas de opresión. Teniendo como perspectiva la trayectoria histórica constituyente fundamental de las Américas que se funda a partir de la colonialidad del poder y conocimiento, junto con la idea y jerarquías de carreras (QUIJANO, 2005). Nuestra discusión se guía

\footnotetext{
${ }^{1}$ Doutoranda em Letras e Linguística, Mestra em Comunicação, Bacharela em linguística e Licenciada em Letras Língua Portuguesa pela Universidade Federal de Goiás. Bolsista CNPq. Goiânia, Goiás, Brasil. E-mail: ludjornalismo@gmail.com. Artigo adaptado de um dos capítulos da dissertação da autora intitulado "Todo Mundo Odeia o Chris: Performatividade e vulnerabilidade do corpo negro à linguagem midiática". Trabalho apresentado no I Seminário Latino-Americano de Estudos em Cultura - SEMLACult, Foz do Iguaçu/PR, Brasil, 2017.
} 
en la construcción de la masculinidad negro y la forma en que está situado dentro de un doble narcisismo (Fanon, 2008), el cuerpo deseado, viril, exótico como se ha visto como una amenaza, la competencia y necesita ser controlado. El espectáculo se mueve en el contexto local brasileño y entrar en diálogo en el curso de la diáspora de los cuerpos negros y lucha contra el racismo y la existencia de transacciones de estos cuerpos. La realización de actos de habla que realizan acciones reales sobre el tema negro, dictando vidas que importan y que son considerados una amenaza a la libertad de los opresores, la configuración, la neurosis racial brasileña (GONZALEZ, 1984) que sólo ve T.M.O.C como un entretenimiento, pero en cualquier momento elle trae la denuncia de la violencia racial y la forma en que se considera como natural.

Palabras claves: cuerpos negros, masculinidades negras, Todo el mundo odia a Chris, medios de comunicación, la colonialidad / decolonialidad.

\begin{abstract}
Our main goal is to discuss how the effects of language / language say / do (AUSTIN, 1998) subalternized bodies and how this can provide us with traces for a critical reading that focuses on decolonial thinking (WALSH, 2009) and non-extermination, physical and symbolic, of lives and other masculinities. In order to problematize, especially, the visibility/invisibility of the black bodies and the construction of prefigurations on such a denominated body of masculine, we bring the series sitcom. Everybody hates the Chris (2005) translated-dubbed like index of how the media narratives reiterate the experiences and perform acts of language constituting spaces and forms of oppression. This has as a perspective the critique of the imperial historical trajectory in the Americas that is based on the coloniality of power and knowledge, together with the idea of race hierarchy (QUIJANO, 2005). Our discussion focuses on the construction of black masculinities and the evoked metapragmatic acts, placing it within a double narcissism (FANON, 2008), of a desired, virile, exotic body while being seen as a threat, competition that needs to be controlled. The North American serial when being dubbed reentextualizando to the local brazilian context and inserts itself in dialogue within the diaspora of the black bodies and the anti-racist transactional struggle and re-existence of these bodies. Performing and resuming acts of speech that carry out real actions on black subjects in an oppressive context, dictating lives that matter when configuring, as one of the consequences, brazilian racial neurosis (GONZALEZ, 1984) that only reads T.M.O.C as an entertainment being that at all Instant it brings the denunciation of racial violence.
\end{abstract}

Keywords: Black bodies, black masculinities, Everyone hates Chris, media, coloniality/decoloniality.

\title{
1. Introdução
}

Nosso principal objetivo é discutir como os efeitos de língua/linguagem dizem/fazem (AUSTIN, 1998) corpos subalternizados e de como isso pode nos fornecer traços para uma leitura crítica que vise potencializar práticas com e para o pensamento decolonial (WALSH, 2009) ao acionar uma outra visão para o não extermínio, físico e simbólico, de vidas e outras masculinidades. A base teórica passa pela intersecção entre os estudos da linguagem e da comunicação, bem como, estudos midiáticos, de performatividade dos corpos e invenções das hierarquias da diferença.

O percurso de discussão passa por autores como Quijano (2005) e Mignolo (2003), que trazem o termo 'raça' como uma arma construída socialmente, uma das invenções que dão início a modernidade e a colonialidade nas américas, ao classificar a humanidade, os corpos e as subjetividades por hierarquias conforme suas diferenças. No entanto, a metanarrativa articulada pela modernidade traz a homogeneidade a partir de um protagonista um sujeito 
branco, eurocêntrico, cristão, heterossexual, escolarizado, de classe alta, com uma história tida como oficial, com uma língua, nação, uma verdade.

De forma que aquele que não se adequa ao padrão, à verdade de vida autorizada, se torna um corpo que não importa ao poder e são, muitas vezes, exterminados tanto fisicamente, quanto simbolicamente pelo apagamento/silenciamento de suas diferenças e narrativas. Isso se naturaliza nas práticas simbólicas (GEERTZ, 2004) ao constituir a ideia de cultura no ocidente se atrelando à trajetória compulsória e violenta da diáspora negra e moldando metapragmaticamente nossa produção e escolha de significados.

Traremos isso para possíveis interpretações do corpus, o seriado sitcom Todo mundo odeia o Chris (2005), transmitido entre 2006 e 2016 no Brasil em versão dublada e em TV aberta pela Rede Record. A narrativa se baseia na vida do comediante norte americano Chris Julius Rock III e se passa entre 1982 e 1987 nos Estados Unidos, Nova York. Em síntese, conta sobre um menino negro, Chris, que vive com sua mãe Rochelle, seu pai Julius, sua irmã Tonya e seu irmão Drew em Bed-Stuy, bairro central do Brooklyn na cidade de Nova York. Considerado um bairro muito perigoso, o que, no seriado, é associado à ideia de praticamente não existirem pessoas brancas morando neste bairro.

A vida de Chris é retratada em vários espaços, como na escola primária Corleone, onde é o único negro da escola, e no ensino médio na Tattaglia, onde é o único negro da sala. Cada episódio retrata uma situação que Chris passa no dia a dia, seja na escola, no trabalho ou na rua na qual características tidas como negras são ligadas à estereótipos e modos subalternos de sobrevivência dessa comunidade.

Esse seriado sitcom também coloca em cena uma representação paródica do seriado Todo mundo ama Raymond, que narra a história de um homem branco que vive com sua família numa grande e confortável casa em Long Island, EUA, e o seu conflito gira em torno apenas da constante visita de seus pais que vivem no outro lado da rua. Todo mundo odeia o Chris ${ }^{2}$, lançado logo após o término de Todo mundo ama Raymond, constitui uma sátira a partir de outra realidade social, transcrevendo o que Segato $(2005$, p. 10) aponta, quando observamos o não-dito, como sendo o resgate de "um signo ausente do texto visual geralmente associado ao poder, à autoridade e ao prestígio".

Um dos recursos que T.M.O.C. utiliza para tornar o seriado irônico e sátira do poder é o Narrador over que juntamente com a narrativa fragmentada em flashforward e feedbacks (previsões do futuro e imagens do passado) questionam o lado censurado, violento e

\footnotetext{
${ }^{2}$ Referido, a partir de agora, pela sigla T.M.O.C por questões de simplicidade.
} 
preconceituoso das/nas interações sociais. Herança do movimento fílmico Blacksploitation, em que personagens negras protagonizam, dirigem e escrevem seus filmes, T.M.O.C reescreve suas experiências como homem negro norte-americano apontando problemas da ideológica euro-anglocêntrica.

E como aliar tal narrativa de produção norte-americana a uma interpretação de repertório brasileiro? Toma-se como partida que o texto de T.M.O.C. ao ser traduzido e dublado para a inteligibilidade brasileira não são apenas teve uma transposição de códigos, mas sim uma reentextualização a partir de uma recontextualização da narrativa, inclusive para que se conquiste o público e que este seja afetado e se identifique com o texto (MARTINS \& AMORIN, 2013). Assim, o que importa para nossa discussão, então, não é a produção e sim a interpretação, quem interpreta, quais recursos e escolhas histórico-culturais dados sentidos são atribuídos à narrativa.

Além disso, a tradução e a dublagem, entre a produção e a interpretação, são possíveis por serem contextos constituídos por uma epistemologia de opressão de base euro-anglocêntrica, que compartilham, de formas diferentes, em termos de projetos globais coloniais (MIGNOLO, 2003), a ritualização da colonialidade do saber/poder. E, ainda, são contextos formados pela expressiva diáspora negra e a segregação simbólica e física dos corpos que se remetem à negritude. Obviamente, esse projeto global colonial é modificado nos locais, estruturando formas de opressão específicas que vulnerabilizam pejorativamente os corpos negros e os barram aos direitos e espaços de prestígio. Nesse meio, o seriado traz intersecções entre raça, classe, gênero, que intensificam a opressão dos corpos e, principalmente, os corpos negros por redes institucionais, históricas e sociais de poder.

De maneira que não podemos homogeneizar práticas de vida de sujeitos considerados homens negros como iguais a vida de homens brancos, em que muitos dos primeiros eram grandes guerreiros filhos de príncipes arrancados de seu povo por europeus e lançados pelo mundo, massivamente nas américas. Se é que podemos ao menos traçar inicialmente o que venha a ser masculinidade, tenhamos em perspectiva que são masculinidades, várias formas de performar uma identidade de gênero, esquematizada pelo homem universal como sendo apenas aquela heterossexual e patriarcal. As masculinidades negras ao serem moldadas pela ideologia eurocêntrica do que venha ser homem e de como esse deve exercer uma masculinidade irrepreensível impulsiona ao negro características da animalidade como o posto da racionalidade.

Em vista disso, Austin (1998) traz a noção de atos de fala e sua performatividade como sendo o ato de dizer e fazer, isto é, os enunciados não só descrevem o mundo mas produzem efeitos 
concretos e simbólicos, constroem realidades. São ações performativas que viabilizam a naturalização de determinadas ideologias na sociedade, e os produtos midiáticos se tornam parte, instrumentos e formas de experienciar essas performatividades de mundo. A ação da metapragmática revela lutas metadiscursivas, conjuntos de discursos e dispositivos epistemológicos, que legitimam as avaliações e correções semânticas/indexicais que direcionam a inteligibilidade dos textos (SIGNORINI, 2008).

Isso é a metapragmática, molda, avalia e enquadra como devemos interpretar e compreender os discursos e os metadiscursos que se chocam e se tornam coerentes no processo de significação em uso. Utilizaremos os estudos pragmáticos tendo a linguagem não só como parte do processo, mas também como sendo o próprio processo de construção de sentidos mobilizados pelas trajetórias textuais e históricas evocadas ao ritualizar diferenças.

E ainda, nesse percurso,

o corpo [se torna] vulnerável à linguagem, no sentido de que a linguagem, sendo performativa, opera, faz, e, sendo assim o corpo é feito e efeito, sustentado e ameaçado pela linguagem. Os atos de fala operam não somente a produção reguladora e produtiva sobre aquilo que nomeiam, mas também constituem seus contextos possíveis - a sua historicidade condensada (PINTO, 2013a, p. 35).

Assim, os rituais de linguagem produzem posições de sujeito, categorias identitárias e linguísticas, e os atos de fala, as interpelações e seus efeitos pragmáticos incidem em T.M.O.C. o significando por signos histórico-culturais que retoma o ato performativo e as performances de sentido possíveis em dados contextos. Butler (2003), a respeito disso, se refere à possibilidade de agência linguística existente na brecha entre o ato de fala e seus efeitos, o que favorece uma resposta crítica ao discurso dominante pela ressignificação do que é dito e a capacidade de falha dos efeitos pelo questionamento.

\section{Duplo narcisismo e a colonialidade}

Faremos aqui, um esboço que de forma introdutória pretende trazer algumas abordagens sobre esse tema ainda tão pouco estudado que é a construção de uma dita masculinidade heterossexual negra e de como as hierarquias de ser masculino se articulam em performances/performatividades de linguagem e possíveis expectativas para o corpo negro. Trabalharemos com a narrativa de Todo mundo odeia o Chris escrita e baseada em fatos da vida de Chris Rock, comediante negro norte americano, protagonista adolescente no seriado. T.M.O.C. parte do lugar de fala de um homem negro que ascendeu socialmente ao se tornar famoso pelas piadas "inapropriadas e sarcásticas", e que devido ao seu corpo negro passa por uma trajetória de estigmatização e violência, principalmente, na escola, um lugar que se 
propunha a educar e corrigir. Se faz necessário, então, discutir a performance/performatividade que o corpo e a negritude masculina afro-diaspóricas são indiciados na/pela narrativa do seriado e de como a pedagogia eurocêntrica de saber/poder incidem atualmente sobre esses corpos.

Durante o seriado, as personagens masculinas negras apresentam performances construídas pela intersecção de gênero, raça, sexualidade e classe que os posicionam tanto como "ideais masculinos negros" quanto representações de subalternidade e perigo civil. Atos que são acionados pela linguagem mesmo quando o corpo negro não está presente, e são incididos na recorrência desse estilo corporal, sua referência e mobilidade nos espaços sociais. São atos de fala que reiteram hierarquias sociais organizando as subjetividades a desempenharem os tidos papéis a fim de não excederem o lugar a eles destinado. Por isso, "o objetivo do racismo não é o [sujeito] particular, mas uma certa forma de existir" (FANON, 1969, p. 36) que legitima a violência epistêmica sob o outro (SPIVAK, 2010) e com esse outro.

Nessa relação instituída pela colonialidade Fanon (2008) diz que na criação da polaridade branco/negro o europeu passa a impor o que é e como o negro deve constituir sua identidade tendo como visão alcançar os ideais brancos. A partir desse processo, é retirado do negro a sua condição de humanidade, categoria designada apenas ao branco que pode ter direitos civis e voz social, e o negro passa a ser "apenas" o corpo negro servil. Ainda segundo o psicanalista, essa polaridade faz emergir um duplo narcisismo, pois o branco ao desconhecer a humanidade ao outro nega também sua condição de ter um corpo, o que torna o branco incompleto. Para suprir essa falta, o branco deseja o outro, no entanto, como esse outro esta subalternizado, então, continua refutando-o socialmente como humano.

Esse duplo narcisismo impacta ambos e gera efeitos de generalização do negro como sendo o depositário da animalidade, do corpo, da agressividade libidinal, da potência sexual, dos desejos e da emoção, enquanto o branco se torna ligado à razão ao rejeitar sua corporeidade. Assim, o branco cria espaços nos quais o negro se convence de estar exercendo sua liberdade (como ser desejado sexualmente), o que o impede de reconhecer a condição encarcerada de seu corpo dentro das estruturas históricas instauradas pelo opressor.

Chis: Quem é Lerry Doby?

Srta. Morello: Ele foi o segundo negro no beisebol, [com ar sonhador e excitado] mas ele era mais alto do que o Jack e mais... encorpado, tinha ombros fortes e um perfil de novio ${ }^{3}$, o uniforme do Cleveland Indians fazia jus à pele caramelada dele, e o jeito que ele balançava o taco... ahhh

Narrador over: Nada de febre da selva, ela tava tendo um ataque selvagem...

\footnotetext{
${ }^{3}$ Sic. É pronunciada no seriado como sendo uma palavra espanhola. Isso pode estar relacionado à noção de romântico e sensual ligado a sujeitos latinos.
} 
Nesse trecho do episódio Todo Mundo Odeia o Novato ( $3^{\mathrm{a}}$ Temporada - $9^{\circ}$ Episódio) apontase um índice de como a racialização da sexualidade funciona como alvo de desejo pela mulher branca. Durante todo o seriado, a Srta. Morello incide atos de fala que naturalizam e inferiorizam os negros em sua posição de subalternidade. Porém, isso se contradiz quando ela se depara com um homem negro emasculado, passando a expressar excitação a respeito desse sujeito. No trecho do episódio acima, Chris estava feliz com a chegada de mais um negro na escola e a Srta. Morello ao comentar sobre o fato compara essa felicidade de Chris ao encontro de dois conhecidos jogadores negros de beisebol americano, Jackie Robinson e Lerry Doby.

Srta. Morello: E Malvo, com educação apropriada você poderia fazer tantas coisas, você poderia ser lixeiro, motorista do carro do lixo, recolher o lixo do carro do lixo, uma lista infinita.

$[\ldots]$

Srta. Morello: Chris, eu acho que esse é um ótimo jeito de tirar o seu pai das ruas.

Narrador over: E mandar pra cama dela.

[...]

Srta. Morello: Chris, Malvo, infelizmente eu tenho más notícias.

Chris: O quê?

Srta. Morello: Malvo, fizeram uma pesquisa de antecedentes sobre você e descobriram que acabou de sair da cadeia. E mesmo que eu ache essa dança com o perigo excitante e estimulante [passando as mãos nas coxas]... outras pessoas morrem de medo disso e querem que você saia.

Chris: Que outras pessoas?

Srta. Morello: Digamos... as autoridades maiores.

Narrador over: Digamos... os branquelos.

(Todo mundo odeia ex-presidiário - $3^{\mathrm{a}}$ Temporada - Episódio 17)

Malvo é considerado um homem negro que causa medo no Brooklyn por ser um expresidiário, porém, agora solto, ele quer a ajuda de Chris para ter educação escolar e conseguir se inserir na sociedade. Chris pede ajuda para a Srta. Morello, sua professora branca de ideais nacionalistas, para ver como Malvo poderia prosseguir com os estudos. A Srta. Morello no seriado relaciona o corpo do homem negro a aspectos de sexualidade exacerbada, de forma erótica, exaltando uma virilidade desejada e o suposto perigo que esse corpo pode proporcionar, mas abre mão de reconhecer esse corpo como humano e com direitos iguais. A professora performa uma integração subordinada e assimétrica, caracterizada e legitimada pela violência simbólica que limita o espaço social a esse corpo e o reconstrói a partir de um sexismo racializado ligado a hipersexualização. Assim, as

identidades masculinas subalternas [são lugares] da contradição entre sistemas de poder diferentes - a estrutura das classes, o sistema dimórfico dos gêneros, as práticas e discursos racializantes - [que] se [combinam] interseccionalmente, [na produção de] novas diferenças, desigualdades e vulnerabilidades (PINHO, 2004, p. 66).

Esse processo rompe com o padrão masculino patriarcal branco, que constrói não só o feminino como subalterno, mas também outras formas de exercer a masculinidade fora das concepções alinhadas de gênero e sexo. Para Pinho (2004), o sujeito masculino se encontra 
nas mobilidades das relações de poder heteronormativas que em dada situação pode tanto o exaltar quanto em outra o subalternizar. O duplo narcisismo (FANON, 2008) proporciona maior visibilidade para certas corporificações do que outras, isso porque sendo o discurso dominante regido pelo padrão de homem branco se elaboram formas de interpretar as ações que privilegiam esse padrão.

Uma das formas de correção dos usos dos corpos é impedir o negro ao desempenho da intelectualidade e designar esta nomeação ao branco, atuações tidas, muitas vezes, como afeminadas, mas que se tornam menos marcadas ao homem branco, imune a marcações por ser a referência, do que ao homem negro destinado a ter uma sexualidade predatória indiscutível e marcada. Em relação a isso, Greg, amigo branco de Chris, se performa como um nerd em crise de identidade, filho de pai solteiro, morador do bairro italiano e descendentes destes, é visto como o intelectual da turma e, ao contrário de Chris, o comportamento de seu corpo nunca é questionado. Mesmo estando acompanhado de Chris, Greg é tratado explicitamente de forma diferente, reconhecido pela sua genialidade e referência de boas notas, e Chris por ser considerado um negro do gueto.

No entanto, Chris não se adequa a performance de um dito "negro heterossexual tradicional", que o forçam a ser um homem negro garanhão, e quando algum índice desse padrão é retomado pelo seu corpo há uma exaltação e positivação do feito. Assim, é posto como a única forma do corpo negro fugir dos ataques da sociedade é validar o discurso dominante, mesmo que para isso o subalternizado tenha que rejeitar o que seu corpo quer ser para se tornar o que o outro quer que ele seja. Para deixa de ser perseguido e violentado, Chris tenta fazer esportes na tentativa de conseguir reconhecimento na escola, pois percebeu que esse ato atraia garotas e o respeito das pessoas. Porém, Chris não se dá bem com nenhum esporte, mas ao retomar a prefiguração de que "todo é negro bom em esportes", Chris é forçado a se inserir nos times e contradizendo a expectativa da prefiguração.

Outra ação de Chris que o torna conhecido, temporariamente, como o "rei das meninas" ocorre quando uma fofoca se espalha pelo bairro e pela escola de que ele ficou com a Tasha, uma garota disputada por outros garotos do Brooklyn. Essa notícia, que era falsa, pois a Tasha apenas deu um beijo no rosto de Chris, é espalhada e modificada pelos garotos de seu bairro e em seguida por toda a escola, aderindo ao estereótipo viril do homem negro pegador, o que chama a atenção de outras garotas que passaram a se interessar por ele, recebendo elogios até de Caruso e da Srta. Morello. Essas validações, marca, além disso, um corpo que indexa dadas interpretações coerentes a uma historicidade do ato de fala que quando são alinhadas ao discurso dominante recoloca o subalternizado em lugares permitidos pelo simbólico. 
Greg: Você beijou a Tasha?

Chris: Bom, tecnicamente, ela que me beijou. Não foi um beijo, beijo... ela só me beijou na bochecha.

Greg: Que bochecha?

Chris: Essa aqui? [indicando com o dedo]

Greg: E... quando aconteceu?

Chris: Ontem ela teve medo de um rato e eu fui pegar pra ela, então, ela me deu uma bitoquinha.

Narrador over: Eu sei o que eu disse, mas também sei o que o Greg pensou...



$[\ldots]$

Meninas brancas: Oiiii, Chris!

$[\ldots]$

Outras meninas brancas: Oiiii, Chris!

$[\ldots]$

Caruso: Ai bonitão achei que você não era de nada.

Srta. Morello: Iiii olha só, não é que ele tem borogodó!?

(Todo mundo odeia o mentiroso ${ }^{4}-2^{\text {a }}$ Temporada - Episódio 4)

Nessa retomada inventiva de um imaginário sobre o desempenho sexual e exótico do homem negro em oposição e competição com o homem branco. Categorias que trazem um tom ontológico inquestionável pela naturalização histórico-cultural que atravessa e significa os corpos com indexicalidades normais legitimas mesmo antes de seu nascimento, determinando suas ações e os contornos sociais desse corpo (BUTLER, 2003). O que sustenta a fetichização que torna o corpo negro apenas objeto sexual para o branco, mascarando pelo discurso de liberdade sexual o efeito de domar o negro para o ato de servir o desejo do outro dominante, que pretende ser completo por aquilo lhe falta, o corpo.

Srta. Morello: Chris, não há nada pior que estereótipos raciais, nós já vimos isso mil vezes, [com ar sonhador] homem negro alto sem camisa, com o vocabulário cheio de gírias, o corpo suado do trabalho no campo, a testa marcada... com um brilho ardente... onde eu estava? (Todo mundo odeia a Bed-Stuy - $3^{\text {a }}$ Temporada - Episódio 6)

\section{Corpos ameaçadores e controlados}

Esse corpo selvagem e estimulante, de linguagem indecifrada e comportamento nãocivilizado, é enquadrado pela heteronormatividade que afirma a superioridade do homem

\footnotetext{
${ }^{4}$ Disponível em: https://www.youtube.com/watch?v=iaX3LGT8DEM. Acessado em: 4 de março de 2017.
} 
negro em relação à mulher negra, configurada como a mais subalterna nas relações de poder (SPIVAK, 2010). Isso "se constitui através da normalização do negro heterossexual, representado pela emblemática virilidade de sua força física, agressividade, violência, grande apetite sexual e pênis potente" (LIMA \& CERQUEIRA, 2007, p. 7). Assim, essa prefiguração configura um corpo marcado como sendo

o Negão, [...] o oposto do Neguinho na sua preocupação com a virilidade, ele seria fisicamente forte e dotado com uma excepcional capacidade sexual. Ele é ameaça ao homem branco por seu apetite sexual insaciável e pela sua diabólica sensualidade, irresistível para a mulher branca, este mito do homem negro hipersexualizado é veiculado exaustivamente pela TV (SOUZA, 2009, p. 104).



(Julius e o servidor da receita - Todo mundo odeia o novato)

No entanto, esse corpo emasculado precisa ser controlado para que não revide as relações de poder, pois "quando um homem negro não está submisso, colocando sua força a serviço do status quo, está fora de controle, tornando-se uma ameaça” (SOUZA, 2009, p. 106). Julius, pai de Chris, retoma a performance de como o negro emasculado é tanto temido quanto controlado. Julius tem como lema o trabalho duro e a dignidade que se pode tirar dele, sabe o preço de tudo que é gasto e tenta economizar o possível, já que os seus dois empregos não são suficientes para sustentar a família. O trabalho age sobre o corpo de Julius, musculoso e desejado pelas mulheres do bairro, o disciplinando, controlando sua força para benefício do patrão branco, que o ordena autoritariamente a fazer as atividades.

No episódio Todo mundo odeia o novato ( $3^{\text {a }}$ Temporada - Episódio 9), Julius, temendo que a receita peça de volta o chegue de devolução do imposto de renda, vai até a receita perguntar se há possibilidade disso acontecer. O servidor da receita ao ver Julius fica na expectativa que ele faça algo agressivo, violento e tenta evitá-lo. Mesmo Julius apenas querendo tirar uma dúvida o servidor fica aterrorizado e só se acalma quando Julius vai embora. Ao contrário da prefiguração de ameaça, Julius além de ter medo de coelhinhos, é um homem que age de maneira submissa, não age com violência, procura pensar antes de fazer algo, realiza trabalhos domésticos e aconselha pessoas. 




Todo Mundo Odeia linguiça

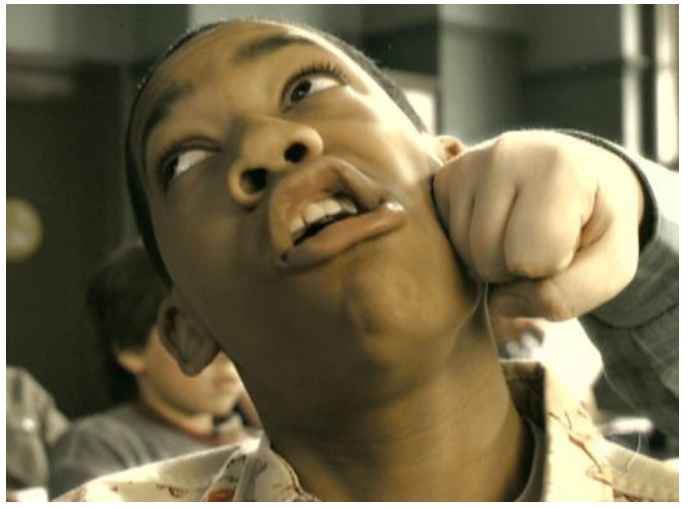

Todo mundo odeia o Tattaglia

Outra forma de controle é a violência física, uma forma de correção do corpo que não corresponde ao ideal masculino negro. A violência física, decorrente da simbólica, é um ato metapragmático que avalia o corpo negro nos espaços, como a escola e o bairro onde mora, já que outros negros desses espaços ao serem jogadores de beisebol se tornam reconhecidos e desejados corporalmente pelo desempenho físico e não-intelectualidade. E Chris, performado como o 'neguinho', ao contrário do 'negão', é visto como um corpo não viril, não desejado, inofensivo e não-atlético tendo sua sexualidade questionada pelo interesse nos estudos pois, "qualquer aquisição intelectual [é tido como] uma perda do potencial sexual" (FANON, 2008, p. 143). Dessa forma, o homem negro tem sua sexualidade vigiada socialmente o ordenando a manter sua masculinização bem definida, a fim de que seja "homem negro de verdade", performando uma virilidade que se parece com o exercício de autonomia, mas é instrumento de dominação da colonialidade dos corpos que dita o que é autorizado.

As proposições de Gilroy sobre a existência de um "esquema de virilidade" na identidade política transnacional negra e a tese de hooks sobre as restrições para a afirmação masculina do homem negro se complementam. Elas nos permitem compreender que tomar a virilidade como fator explicativo da masculinidade negra, implica considerar o efeito causado pelo sistema de supremacia branca patriarcal capitalista. A virilidade do homem negro não pode ser tida, nesse caso, como um valor masculino em si, mas sim como um efeito reativo a uma condição de subalternização racial inerente a sociedades ex-escravistas, onde o modelo hegemônico que deve ser alcançado é o do patriarcado, o poder viril exercido plenamente pelo homem branco (NKOSI, 2014, p. 81).

O projeto de nação instituída pela colonialidade/eurocentrismo do saber/poder e que forma a metanarrativa da modernidade constitui o imaginário e o simbólico tendo como fundação o imperialismo de uns sob outros como maneira de organização aceita. A ideia de modernidade se alia a ideia de raça (QUIJANO, 2005) o que se torna argumento legitimo do europeu, autonomeado como superior e melhor, para o processo de diáspora forçada e escravização de reis, rainhas e guerreiros africanos considerados como inferiores, não produtores de conhecimento e de práticas simbólicas demonizadas. Um projeto de dominação mediante a 
projeção de um homem universal que visa tornar a cultura europeia a melhor e referência de saber/poder. Um ideal que ainda se perpetua nas relações sociais ao atualizar o lugar do negro como o de não prestigio, a padronização do que pode ser o homem negro, retomando a colonialidade das subjetividades, das formas como esse sujeito pode se ver, se comportar e ser nomeado.

Os efeitos da colonialidade incidem sobre os corpos negros arquitetando o poder autorizado, selecionando vidas que valem a pena ao Estado e que podem interferir politicamente nos espaços e discursos, e quais masculinidades serão aceitas ou exterminadas. O negro traz o percurso compulsório e violento da diáspora como o corpo de trajetória apagada e silenciada pelo discurso hegemônico oficial que deslegitima outras performances, outras formas de viver que não seja a de referencial ao "melhor", à norma. Gilroy (2001) traz a necessidade de se pensar os corpos negros regionalmente e translocalmente, além do tráfico negreiro e a partir da comunidade do atlântico negro. Indicando uma rede de resistência à segregação epistêmica da negritude nas américas, tendo em perspectiva que a discriminação racial não acontece apenas com o indivíduo, mas com todo um grupo que é violentamente marcado, configurando empecilhos sociais para sua existência.

Por isso, um traço em comum que perpassa a negritude diaspórica é uma unidade plural que conduz ao sentimento de deslocamento e de reconstituição simbólica em tensão racial frente a colonialidade/modernidade. Nesse sentido, a concepção de diáspora que permeia nossa análise é uma metáfora que marca o corpo negro e sua produção simbólica, o barrando nos espaços sociais e o reescrevendo em identidades que o desautorizam à potência de existir enquanto humano. O 'retorno ao lar' pode ser tido como uma posição decolonial que possibilita as práticas de re-existência dos sujeitos subalternizados mesmo imersos em forças eurocêntricas que o tentam apagar da história global. Assim, a diáspora africana é um pensamento político contra hegemônico, a partir de uma necessidade de se descobrir, de reafirmar uma identidade fragmentada para além dos limites da nação. Sendo que essa homogeneíza o tempo, o espaço, o saber e os sujeitos tirando a possibilidade de exercer a diferença sem ser sancionado.

A perspectiva decolonial, segundo Walsh (2009), tem como perspectiva transcender a colonialidade, a violência epistêmica da modernidade e de seu padrão mundial de poder que continuam se ritualizando em nossas ações cotidianas. É um posicionamento não de simples superação da colonialidade, mas do uso de ferramentas políticas, epistemológicas possíveis para a construção de relações sociais pautadas na superação das opressões da 
modernidade/colonialidade/globalização/Estado, estruturas que configuram uma ideia geopolítica mundial desigual.

\section{Invenção dos corpos negros e a intelectualidade não legítima}

Performar um sexo dentro de regimes binários, que deve ser alvo de desejo do outro definido como destino natural do ser "homem ou mulher de verdade", é recorrer aos efeitos das "instituições definidoras: o falocentrismo e a heterossexualidade compulsória" (BUTLER, 2003, p. 9). Butler (2003) ainda propõe uma desconstrução das categorias de sexo e gênero, pois são polaridades políticas impostas sobre os corpos a partir da heteronormatividade. Assim, segundo a autora, gênero não se comporta apenas como os aspectos culturais que ditam como o sexo, feminino ou masculino, devem se comportar, mas é a convenção, o aparato discursivo/cultural e a imposição de um saber que estabelece as concepções de sexo como algo biológico e gênero como algo que esse biológico determinou. Invenções que afirmam relações de poder mediante a nominação dos corpos e de suas partes, e de como isso organiza a sociedade hierarquicamente a partir de uma ciência autorizada e tida como verdade.

O que cria a ilusão de componentes naturalmente corporificados e fixos que devem convergir a um ponto localizável arranjado pelo imperialismo epistemológico ocidental e capitalista. Que para os homens negros imprime categorias regulatórias que os mantém como o corpo macho ideal, em termos de desejo, mas se torna o local que reafirma o branco como aquele que tem o sexo e o falo, simbolicamente o poder falocêntrico, e não apenas o pênis como índice de sexo sem o poder (NKOSI, 2014). Tal poder mobiliza os mecanismos culturais de opressão que sanciona quando esse corpo negro masculino é duvidoso e passível de ser questionado, que desvia da unidade fabricada pelo branco. Isso é uma das autorizações concedidas à performance de Caruso, que bate em Chris como forma de se reafirmar enquanto chefão da escola e de sancionar Chris não só por ser negro, mas também por não efetuar a masculinidade do negão.

Caruso, ao realizar esse feito não só fisicamente, mas também com palavras, nomeia Chris como 'neguinho', desqualificando esse corpo e o tornando infantilizado, de fala não autorizada e vulnerável a rituais de linguagem ofensiva. Tanto que Caruso não agride outros negros que aderem ao porte ‘durão' ou quando Chris está em companhia de outros negros que praticam esportes ou são violentos. A escola, situada no bairro italiano, é um espaço em que a diferença é ressaltada, é onde Chris se vê como negro pelo seu relacionamento com outros alunos e professores brancos que o nomeiam como um negro marginal, "filho da droga, sem 
pais, com vários irmãos, miserável, que usa gíria e mora no gueto”. E ainda culpam Chris pela violência recebida por ser negro.

Nesse sentido, $\operatorname{hooks}^{5}$ (2015, p. 677) afirma que a heteroidentificação racial e de gênero pode ser tecida também com relação ao desempenho escolar" e de como esse negro é percebido na escola. Chris, o único negro no Corleone e o único negro na sala do Tattaglia, não tem um corpo forte, não sabe esportes, cozinha bem e gosta de estudar, sempre é agredido pelo Caruso. A negritude constituída hegemonicamente através da normalização do negro heterossexual identifica Chris como um negro fora da ordem atribuída pelo padrão branco. $\mathrm{O}$ que o opõe ao seu irmão Drew, que não gosta de estudar, aparenta ser mais velho que Chris, é "maior e melhor", é um garoto negro que sempre se dá bem no que faz, é desejado pelas garotas do bairro, tem habilidades esportivas, de dança, de luta, é popular na escola, mas não consegue notas boas.

Ainda segundo a autora, por ser, geralmente os negros são associados apenas ao corpo e nunca à capacidade intelectual, portanto reverter essa ordem pode também se tornar uma ameaça caso esse sujeito se torne pensante. Isso força os homens negros a se formarem como sujeitos "ensinados que o "pensar" não é um trabalho valioso, que o "pensar" não os ajudará a sobreviver" (hooks, 2015, p. 679). Na escola, Chris, apesar de estudar muito, é sempre reconhecido como o ponto fraco do desenvolvimento da classe de aula. "Mr. Thurman: você não é dessa turma. Chris: porque não? Mr. Thurman: Você é negro, é um cara negro[...] Narrador over: Ele tava com medo é que causasse uma desvalorização da turma" (Todo mundo odeia a Tattaglia). Chris se torna, então, uma metáfora da transição entre o chamado gueto, a vida marginal e não-intelectual, para a civilidade, a educação e uma vida melhor, é um depositário de esperança e mudança para a família negra e pobre de Chris.

Com essa perspectiva, a mãe de Chris o matricula em uma escola que fica em outro bairro, onde só tem professores e alunos brancos, em vez de uma escola em seu bairro, onde só tinham pessoas negras e "delinquentes". Esse ideal que alia corpo e intelectualidade formou um imaginário que coloca os brancos como os sábios e inteligentes. Atingir esse ideal, percebe hooks (2015) ao analisar autobiografias de homens negros durante a fase escolar com a maioria de alunos brancos, é uma recorrência: o mal desempenho escolar dos homens negros nesses espaços, muitas vezes, é atribuído e culpabilizado somente à capacidade individual do aluno, não se considera as intersecções de desigualdade que esse corpo se torna

\footnotetext{
${ }^{5}$ bell hooks, nome de sua avó e pseudônimo de Gloria Jean Watkins, prefere assinar suas obras em letras minúsculas pois, segundo ela, o mais importante seus trabalhos é a substância, o valor está nas ideias e não em quem é a autora.
} 
afetado, resultado de aspectos históricos, silenciados e pagados, que formulam e categorizam esse desempenho.

Narrador over: Minha mãe achava que ir a uma escola de brancos ia garantir uma educação melhor e mais segurança pra mim... errou...

[...] [o corredor da escola Caruso pisa de proposito no sapato de Chris]

Caruso: Pisante bacana, pixaim.

Chris: Pixaim? Sua mãe não me chamou assim quando eu pisei na cama dela ontem a noite.

Narrador over: Você acha que eu pirei geral né, mas se eu deixar passar batido ele vai ficar me azucrinando pra sempre. Não dava pra sair no braço, mas eu achei que eu ia conseguir encarar ele na moral.

Caruso: Como é que é?

Chris: Eu gaguejei?

Caruso: Você sabe quem eu sou?

Chris: Pisa no meu sapato de novo que vou te mostrar quem eu sou. Eu não amarelo. Sou da Bed-Stuy, moleque. Eu trago uma gangue inteira pra cá. Vou te cobrir de tanta pancada que vai dormir de amoleta.

(Todo mundo odeia o episódio piloto- $1^{a}$ Tempodada - Episódio 1)

No episódio descrito acima, Todo mundo odeia o episódio piloto, Chris se mostra um garoto perigoso para que Caruso tenha medo, o que é um ato de fala infeliz, pois Chris não tem intensão de brigar, não tem contato com gangues e não prática atos violentos. Ainda em ambiente opressor, a forma de assumir uma resistência física e de "perigo do gueto" é tomado como maneira de "muitas vezes, em contextos educacionais predominantemente brancos, homens negros assumem o papel de menestrel do gueto como um modo de se proteger da raiva racializada e branca" (hooks, 2015, p. 685). O que condiciona a um confinamento desses corpos em classes especiais, punição escolar, nomeações de loucos e encrenqueiros, que os deslegitimam ao insistirem em falar e assumir posição de igualdade. Além desse silenciamento, o desestimulo se torna frequente a fim de expulsar esse corpo do espaço de prestigio.

Os atos de fala se articulam na/pela linguagem por estruturas simbólicas, pela pedagogia anglo-eurocêntrica de conhecer o mundo, de forma que o processo comunicativo ao nomear perpassa a reflexão, a avaliação pelos usuários se tais usos da linguagem são possíveis e permitidos. Isto é, o corpo em interação está ao mesmo tempo constituindo materialidade linguística e exercitando a linguagem quanto também indexicando significados sobre a linguagem e como a linguagem deve ser usada. Invenções que criam quadros metapragmáticos de leitura social, de significação dos gestos simbólicos e dada concepção do mundo.

Srta. Morello: Então, Chris, soube que o nosso novo inspetor está causando o maior rebuliço.

Chris: Obrigada!

Srta. Morello: Chris, somos amigos, não é?

Chris: É...

Narrador over: Não...

Srta. Morello: Eu não participo do programa de inspetores, mas, como amiga, acho que devia ir mais devagar.

Chris: Porque? Acabou de dizer que eu impressiono?

Srta. Morello: a mim sim, mas o resto dos alunos, eles odeiam você. 
Chris: mas eles sempre me odiaram...

Srta. Morello: Pois é, mas odiavam você porque é negro, agora eles odeiam você porque age como um cretino. Narrador over: E porque eu sou negro...

Srta. Morello: Então qual o problema?

Srta. Morello: Você deu um golpe de judô no Rodney por usar boné.

Chris: Eu só cumpri o meu dever.

Srta. Morello: Eu sei que os excluídos podem ficar muito agressivos quando conseguem saborear o poder. Olha Chris, você é apenas um inspetor, vá com calma.

(Todo mundo odeia ser inspetor ${ }^{6}-2^{\mathrm{a}}$ Temporada - Episódio 12)

Controlar esse negro prefigurado como ameaça passa pela desqualificação das ações dele como corpo que pode desestabilizar a autoridade do masculino dominante, mas que não pode se efetivar nos termos do discurso dominante como o masculino universal. É um ato de docilizar e adornar o sujeito que não é legitimado para a correção, mas para ser corrigido e agir conforme os representantes do poder ditam, o que não ocorre com Caruso que é livre para exercer violência. "Jovens negros, desproporcionalmente numerosos entre os pobres, vêm sendo socializados para acreditar que a força e a resistência física são tudo o que realmente importa" (hooks, 2015, p. 679). Por isso, reprimir o corpo negro, o medo que supostamente é inerente a ele, o colocando em seu devido lugar nos espaços sociais, aponta "que homens negros [sejam forçados] a esses requisitos de modo a provar que eles são ensináveis, que eles podem aprender" (hooks, 2015, p. 686).

Srta. Morello: Gregori você tem um futuro brilhante a sua frente! E Chris isso pra sua família deve ser como ter um P.H.D. Já sabe para qual colégio você vai?

Chris: Quero ir pra academia de ciências do Bronx com o Greg...

Srta. Morello: [Decepcionada] Olha Chris, você se formou no ensino médio, não vamos ser pretenciosos...

Narrador over: Eu nem tinha pretensões pra ser pretensioso.

Srta. Morello: A academia do Bronx é para estudantes exemplares, você deveria pensar em alguma coisa mais realista.

Narrador over: Ela quer dizer uma escola com detectores de metal.

(Todo mundo odeia a formatura - $3^{\text {a }}$ Temporada - Episódio 22)

O que pode ser considerado "um sinal de genialidade em uma criança branca é vista como um problema ou dificuldade quando expressada por meninos negros" (hooks, 2015, p. 680), como não ter pretensões de ir para uma boa escola, sendo isso autorizado ao Greg, que é branco. Essa seleção de acesso ao conhecimento dominante assinala e itera a violência que imprime ao corpo a estagnação do lugar de subalternidade. Tanto que são atos que não só apontam uma ofensa e destroem e reconstroem os corpos a partir da historicidade da significação do uso das palavras, mas indicam como essas palavras retomam força performativa quando endereçadas e ditas por dados corpos. Com isso, o corpo que fala é um corpo que significa e é significado, inscreve e modifica a linguagem e agencia a visibilidade do outro ou não ao processo comunicativo (BUTLER, 2003).

\footnotetext{
${ }^{6}$ Disponível em: https://www.youtube.com/watch?v=lbchs4ThXT8. Acessado em: 4 de março de 2017.
} 
Nesse sentido, Fanon (2008) discorre sobre a cissiparidade que faz o negro ter duas dimensões, duas maneiras de ser agenciado, "uma com seu semelhante e outra com o branco. Um negro comporta-se diferentemente com o branco e com outro negro" (2008, p. 33). Isso é indiciado em Todo mundo odeia o novato quando Albert, um garoto negro, chega à escola de Chris e eles se tornam amigos por terem experiências sociais semelhantes. A identificação entre eles passava pelo mesmo gosto musical, programas de negros, enfrentar ofensas e fazer piadas com pessoas brancas, ao contrário do que acontece com Greg, que tem um repertório de visibilidade cultural-social diferente.

Outra performance é evocada quando categorias sociais se intersecionam e configuram relações de poder quando mesmo o sujeito identificado como negro se torna "quase branco" ao agregar elementos de ascensão e civilidade. Essa leitura regida pelo dominante que aponta o destino do subalternizado como sendo o topo da hierarquia indica que "quanto mais assimilar os valores culturais da metrópole, mais o colonizado escapará da sua selva. Quanto mais ele rejeitar sua negridão, seu mato, mais branco será” (FANON, 2008, p. 34). E mais se aproximará do padrão de aceitação, o que não significa ser tratado de forma igualitária. Por isso, "a injustiça social global está assim intimamente ligada à injustiça cognitiva global, de modo que a luta pela justiça social global também deve ser uma luta pela justiça cognitiva global" (SANTOS, 2007, p. 79).

Srta. Morello: Chris, será que eu posso falar com você?

Chris: Claro, qual é o assunto?

Srta. Morello: Eu sei que a sua candidatura está difícil, mas acho que tem muita chance de ser presidente do grêmio, se quiser de verdade.

Chris: Como assim?

Srta. Morello: Precisa superar sua mentalidade de favelado...

Chris: Mentalidade de favelado? Eu não tenho essa mentalidade!

Srta. Morello: Tem sim Chris, uma favela psicológica. Você não consegue eleitores porque não sai de sua zona de tranquilidade.

Chris, ao ser interpelado pelas categorias de raça e gênero ainda conta com a classe como barreira ao não poder mudar de escola devido seus pais não terem dinheiro, a grande distância entre sua casa e a escola, aliar trabalho aos estudos, o que o faz ficar muito cansado durante as aulas, diferente dos outros alunos brancos que apenas estudavam. A hierarquia também é marcada pela classe econômica quando a família de Chris se encontra com um grupo de negros de classe alta que recrutam jovens para o programa João e Maria, "uma organização social de famílias negras bem-sucedidas”. O que exige da família de Chris uma mudança de comportamento durante o encontro com a organização e uma performance de "parecer inteligente" nas conversas com as pessoas ricas. 
E ainda, no episódio, Todo mundo odeia o baile (4a Temporada - Episódio 3), quando Chris vai convidar Denise, filha de pais negros ricos, para o baile de boas vindas da escola, a reprodução da violência se alia a uma ascensão social e a referência ao espaço, o bairro em que Chris mora. Nesse episódio, que faz uma homenagem ao Bill Cosby Show, Chris é prefigurado pelo casal de negros ricos como um menino que vive de caridade e mora em um bairro onde todos usam drogas.

Senhora Blair: Então, Chris! De onde você é?

Chris: Bed-Stuy.

Senhora Blair: Ah, eu já ouvi falar desse lugar! Mandei um jovem de lá para a cadeia. Ele estava vendendo drogas. Todos os jovens de lá usam isso.

Senhor Clint: Você é um jovem que usa drogas?

Chris: Não Senhor!

Senhora Blair: Me diz uma coisa, Chris! Você tem uma família?

Chris: Tenho! Uma mãe, um pai, uma irmã, irmão...

Senhor Clint: E esse povo todo aí é drogado?

Chris: Não Senhor!

Senhora Blair: Em que área do Direito sua mãe atua?

Chris: Ela trabalha num salão de beleza.

Senhor Clint: Tá... E o que é que o seu pai faz?

Chris: Ele tem dois empregos.

Senhora Blair: Ah, então ele é médico e advogado?

Chris: Não... ele dirige um caminhão e trabalha de segurança meio período.

Senhor Clint: Ah... sei! [mostrando-se decepcionado com a profissão]. Bem Chris, igual a maioria das pessoas de Bed-Stuy, nossa filha ai é uma perdida. E em vez de desperdiçar dinheiro numa boa escola particular, decidimos dar uma lição nela e enviá-la para a escola pública de Tattaglia.

Senhora Blair: E ela decidiu nos dar uma lição trazendo você aqui pra casa.

Ribeiro (2012) aponta a performance desses negros em posição de prestigio sem compromisso com a causa racial como sendo "negros passivos", pois não se atentam para uma atuação política aliada a como seu corpo é lido socialmente na realidade das ruas. Ainda segundo o autor, mesmo negros quando ocupam posição econômica e intelectual não têm poder efetivo, são espaços de poder limitado concedidos pelos brancos, já que seu corpo continua sendo nomeado e sistematizado como o outro subalternizado.

Fanon (2008) indica que se o negro existe como objeto na linguagem do branco, no uso de uma sintaxe, de uma morfologia da língua, de um quadro de pensamento, sendo uma representação metafórica da subalternidade. Então, é preciso dominar a sintaxe e a morfologia dessa língua, seu quadro de pensamento, ao desconectar e ressignificar a ideia de negro para si mesmo e para o outro a partir de uma metapragmática crítica que se desdobra sobre o dito e o fazer desse dito historicamente. Assim, as intersecções performativas que impõem uma liberdade aos corpos negros autorizada pelo dominante controla as ações desses corpos imprimindo seus limites e violentando não só sua materialidade cultural quanto seus desejos, sua subjetividade, a visão sobre si mesmo e a forma como deve agir sexualmente para ser aceito/contido. 
Em Todo mundo odeia o professor substituto (2 $2^{\mathrm{a}}$ Temporada - Episódio 14), temos a volta da viagem à África feita pela Srta. Morello, que se depara com Chris vestindo uma camisa vermelha com B- (B menos) escrito nela - nota de sua prova de matemática em que o professor substituto o obrigou a estudar até alcançar nota melhor. Mas sem saber disso, a Srta. Morello interpreta de outra maneira, mais uma vez é uma interpretação que retoma metapragmáticas, como os usos de linguagem devem ser lidos, que parte da significação da cor de pele de Chris. Srta. Morello: Chris, adorei sua camiseta, o quê que ela quer dizer? Chris: (com cara de surpresa pela pergunta) B menos... Srta. Morello: aaahhhh, B menos!!! Essa gíria negril eu adoro... A Srta. Morello preenche a lacuna de sentido sobre o B- por uma prefiguração identitária (PINTO, 2013b) que no momento da fala reconstrói realidades e percursos do imaginário opressor aliando o corpo negro ao único espaço que ele está autorizado a pertencer, o gueto.

Conforme Fanon (2008, p. 44) "um branco, dirigindo-se a um negro, comporta-se exatamente como um adulto com um menino, usa a mímica, fala sussurrando, cheio de gentilezas e amabilidades artificiosas”. Nesse sentido, interpretar o outro é um ato de tradução que na interação retoma invenções sobre os corpos e as posições sociais deles destruindo subjetividades e impondo discursos hierárquicos que invalidam dadas formas de vida. Assim, "a cor da pele ocupa o lugar do significante central que conecta, organiza e totaliza todos os demais elementos. A cor torna-se sinédoque das relações raciais” (SALES JR., 2006, p. 232). O corpo é inscrito e se move na/pela ação da linguagem, de maneira que é direcionado à sua destruição e transfiguração (BUTLER, 2003), para que surja a 'cultura', o ideal de gênero e de desempenho que é orientado pela colonialidade dos corpos apagando a diversidade de atos.

\section{Possíveis considerações finais...}

Todo mundo odeia o Chris ao trazer uma narrativa crítica e sarcástica possibilitada pela visibilidade midiática, já que esteve ao ar em TV aberta brasileira por quase 10 anos, nos direciona a repensarmos o quanto os corpos negros são heterogêneos e transgressores contra a homogeneidade imposta pela colonialidade branca que dita o que é certo ou não. $\mathrm{O}$ protagonismo negro, mediante a experiência de Chris Rock, retoma experiências vividas pelos negros nas américas e que se enraízam, de formas diferentes, ao imperialismo de um saber sobre outro. No entanto, como brasileiros, não somos ensinados a olhar para T.M.O.C para além do simples humor que ele passa, pois, o mito da democracia racial impõe metapragmaticas consideradas validas para que a ideia de nação homogênea, sem violência, de harmonia, de paraíso racial seja preservada. Enquanto isso a denúncia do seriado aponta 
transnacionalmente quais corpos são mortos por homicídio, quais estão presos, quais são analfabetos e que vivem em situações precárias de vida.

O humor, por ser um elemento considerado no Brasil algo não sério, sem importância, se torna o primeiro plano de leitura do seriado, situando a narrativa um entretenimento sem reflexão do que é dito, mas também contribui para 'amenizar' o teor rude, satírico e direto que constitui o contexto de significação do seriado contra o mito da democracia racial e miscigenação no Brasil. O humor, quando é visto aliado a trajetória da narrativa de T.M.O.C revela o quanto o silêncio sobre a discussão e o ato de assumir a existência do racismo na ordem do 'paraíso racial' é velada, proibida e uma agressiva e romantizada neurose cultural (GONZALEZ, 1984). A tarefa performativa que T.M.O.C enuncia para atingir o interpretante pelo ato de tradução e dublagem do texto audiovisual para o português brasileiro, incide em um uso linguístico e produção de sentidos que prioriza a ideologia dominante para o que é tido como engraçado, atualizando as relações sociais sobre os corpos subalternizados e silenciando que a denúncia da violência racial também é necessária no contexto brasileiro.

Gonzalez (1984) ainda aponta que o mito da democracia racial se torna uma fachada para a neurose cultural que omite práticas racistas e sexistas no Brasil. Tal neurose constrói realidades conscientes que ocultam o sintoma racista, que traz certos benefícios ao neurótico e a quem não se encontra na zona de opressão e esquecimento. Essa situação "benéfica" liberta o neurótico da angústia de se defrontar com o recalcamento, mas esse ato se revela como um desconhecimento de si mesmo em prol do esquecimento do outro. Dessa forma, a decolonialidade procura trazer o que é tido como não legitimo, fora dos padrões, que está no esquecimento e no silenciamento das práticas de vida tornando os corpos negros também humanos, uma forma de humanidade diferente, com outras performances possíveis e com várias narrativas de re-existência diaspórica.

Nesse caminho, T.M.O.C retoma o movimento fílmico do Blacksploitation, que é a protagonização, direção e escrita de filmes por negros como critica a branquitude narrativa hollywoodiana. E ainda T.M.O.C procura mostrar não apenas uma ficção das relações sociais, mas insere uma experiência que parte da intersecção de fatores que se aliam ao racismo e nomeiam o grupo negro nas américas, indicando que o imaginário construído pelo angloeuropeu é apenas mais um e que outras formas de viver estão disponíveis, e são usadas subjetivamente. E ter essa visibilidade nos filmes pode, se nos desvencilharmos da lente interpretativa da colonialidade, desembocar em um teor crítico da realidade condicionada e nos voltarmos, segundo Werneck (2003), ao percurso e teia diaspórica globalizada. Esse 
instrumento de visibilidade se direciona, principalmente, pelo deslocamento de signos transculturais do que de uma questão de deslocamento de pessoas.

Portanto, se o racismo é estrutural no Brasil e se interseciona com outras categorias que inventam os corpos e os localizam na arquitetura do poder, é preciso olhar as narrativas midiáticas conforme seu percurso textual histórico que vai além de uma ficção, mas que provocam efeitos reais em nossas vidas cotidianas e em como olhamos para nós mesmos. E ainda, perceber como as performances de corpos são projetadas e sancionadas, efetuando a objetificação do masculino negro como projeto de dominação e ameaça, como corpo que não pode demonstrar afeto e sim virilidade, nomeação dada pelo opressor, o polarizando para o extremo controle pela inspiração de medo, exotismo e incompreensão - também nomeações que se tornaram valores para a significação dos corpos negros masculinos.

De forma, sendo a norma o patriarcado, para conseguir se inserir em dados espaços é preciso demostrar o ideal de masculino negro sem resquícios de feminilidade. Um modelo metapragmático de vida que lhe é impossibilitado de ter o falo do poder, destinado a masculinidade branca do homem universal. Tornando o homem negro o corpo com o sexo sem o considerado uso simbólico do poder, sendo obrigado a aderir ao espaço dado pelo opressor, rejeitando sua forma de ser para conseguir se livrar de uma sanção que o desmascula para a inferioridade. O voltando à práticas de violência que afirmem sua posição de superioridade inventada sobre a mulher negra. É preciso, então, discutir sobre afetos e as diversas formas de se poder ser homem negro e de como o sistema opressor instaurou um espaço que apenas reafirma a não autonomia dos corpos negros e impede desse grupo se unir, e voltar sua força contra a colonialidade do saber, poder e das subjetividades que os encarceram a todo instante tornando suas diferenças nulas para a tomada de palavra.

\section{Referências}

AUSTIN, John L. Performativo-constativo. Tradução: Paulo Ottoni. In: OTTONI, Paulo Roberto. Visão Performativa da linguagem. Campinas: Editora da Unicamp, 1998. 107-144.

BUTLER, Judith P. Problemas de Gênero: feminismo e subversão da identidade. Tradução de Renato Aguiar. Civilização Brasileira: Rio de Janeiro: 2003.

FANON, Frantz. Racismo e Cultura. In: Em defesa da revolução africana. Lisboa: Livraria Sá da Costa, 1969.

Pele negra, máscaras brancas. Trad.: Renato da Silveira. Salvador: EDUFBA, 2008.

GILROY, Paul. O Atlântico Negro. Modernidade e dupla consciência, São Paulo, Rio de Janeiro, 34/Universidade Cândido Mendes - Centro de Estudos Afro-Asiáticos, 2001.

GEERTZ, Clifford. A Interpretação das Culturas. Rio de Janeiro: Zahar Editores, 2004. 
GONZALEZ, Lélia. Racismo e sexismo na cultura brasileira. In: Revista Ciências Sociais Hoje, Anpocs, p. 223-244, 1984.

NKOSI, Devid Faustino. O pênis sem o falo: algumas reflexões sobre homens negros, masculinidades e racismo in: Feminismos e masculinidades: novos caminhos para enfrentar a violência contra a mulher / organização Eva Alterman Blay. - 1. ed. - São Paulo: Cultura Acadêmica, 2014. Pp. 75

PEIRANO, Mariza. Apontamentos sobre rituais, eventos e política. ANPOCS/2002. Disponível em: http://www.anpocs.org/portal/index.php?option=com_docman\&task=doc_view\&gid=4502\&Itemid=3 17. Acessado em: 7 jan. 2016.

PINHO, Osmundo. Qual é a identidade do homem negro? Democracia viva, $\mathrm{n}^{\mathrm{o}}$ 22, Espaço aberto, JUN/JUL 2004. P. 64-69.

PINTO, Joana P. O percurso do performativo. Revista Cult, São Paulo, p. 35 - 36, 01 nov. $2013 a$.

Prefigurações identitária e hierarquias linguísticas na invenção do português. In: MOITA LOPES, Luiz Paulo da (Org.). Português no século XXI: cenário geopolítico e sociolinguístico. São Paulo: Parábola, 2013b.

QUIJANO, Aníbal. Colonialidade do poder, eurocentrismo e América Latina. In: LANDER, Edgardo (org.). A colonialidade do saber: eurocentrismo e ciências sociais. Trad.: Julio Cesar Casarin Barroso Silva. Buenos Aires: Consejo Latinoamericano de Ciencias Sociais - Clacso, 2005.

RIBEIRO, Alan A. Moraes. Blackness: identidades, racismo e masculinidades em bell hooks. Seminário Internacional Fazendo Gênero 10 (Anais Eletrônicos), Florianópolis, 2012. ISSN 2179510X.

ROCK, Chris; LEROI, Ali; MICHAELS, Jim. (BR). Todo mundo odeia o Chris. [seriado]. Criação de Chris Rock e Ali LeRoi, produção de Jim Michaels. $\mathrm{N}^{\circ}$ de temporadas $4, \mathrm{~N}^{\circ}$ de episódios 88. Estados Unidos, 2005.

SALES JR., Ronaldo L. Democracia racial: o não-dito racista. Tempo Social, revista de sociologia da USP, 2006, v. 18, n. 2.

SEGATO, Rita Laura. Raça é signo. Série Antropológica. Brasília: UnB, n. 372, 2005.

SILVERSTONE, Roger. Por que estudar a mídia? São Paulo: Editora Loyola, 2002.

SOUZA, Rolf Ribeiro de. As representações do homem negro e suas consequências. Revista Fórum Identidades. Ano 3, Volume 6 | jul-dez de 2009.

SPIVAK, Gayatry. C. Pode o subalterno falar? Tradução de Sandra Regina Goulart Almeida, Marcos Pereira Feitosa e André Pereira Feitosa. Belo Horizonte: Editora UFMG, 2010.

WALSH, Catherine. Interculturalidad, Estado, Sociedad: Luchas (de)coloniales de nuestra época. Universidad Andina Simón Bolivar, Ediciones AbyaYala: Quito, 2009.

WERNECK, Jurema. Da Diáspora Globalizada: Notas sobre os afrodescendentes no Brasil e o início do século XXI. 2003. Disponível em: http://www.criola.org.br/artigos/Da\%20 Diaspora\%20Globalizada.pdf. 